\title{
Adopting and implementing advanced manufacturing technology: new data on key factors from the aeronautical industry
}

\author{
J. A. D. MACHUCA †**, M. SACRISTÁN DÍAZ† and \\ M. J. ÁlVAREZ GIL
}

\begin{abstract}
The objective of this paper is to take a greater in-depth look at which factors might be considered to be key to the performance of investments made in advanced manufacturing technologies (AMT), given their supposed positive effects, and on the influence that the time these factors are taken into account during the adoption and implementation process can have on that relationship. It provides a specially devised empirical analysis in the aeronautical sector in the south of Spain. A survey of the 20 plants in the population was conducted via a postal questionnaire between July 1999 and April 2001, with a structured interview being held at a later date. The testing of hypotheses was performed by applying the $t$-test to independent samples. The results show that the only factor that has a clear and positive effect on performance is the training of personnel. It can also be seen that a lack of strategic planning contributes to dampening the effects of investments. These results may be of some help to management staff and public administrators in charge of promoting the process of technological innovation, by indicating actions that need to be taken in order to successfully adopt and implement AMT.
\end{abstract}

\section{Introduction}

What the keys are that allow the greatest benefits to be obtained from investments in advanced manufacturing technologies (AMT) and that contribute to maintaining and improving the competitive position of investing companies is a question that is still open to research; and not only for scholars of operations management, but also, and more especially, for company management and for the public authorities whose objective is the strengthening of the capacity for innovation within their industrial fabric. A number of studies (Krafcik 1988, Matthews and Foo 1991, Swamidass and Kotha 1998, Cagliano and Spina 2000) conclude that AMT investment alone does not lead to great improvements in a firm's performance if innovation does not extend to organizational and strategic issues. It would therefore seem to be necessary to determine which other activities and factors affect the performance of investments that have been made, such as investments in infrastructure for example (Boyer et al. 1997, Jonsson 2000).

Firstly in this paper we provide a review of literature dealing with the factors that have been considered key because of some possible positive effects they may have on AMT investment performance. This will allow us to present the questions and 
theoretical hypotheses for this research. Secondly, we shall set out the empirical analysis devised for the plants and facilities that comprise the aeronautical sector in the south of Spain. This analysis is designed to identify which actions contributed to the success of investments in AMT; this success is gauged by the degree to which the previously set objectives were achieved, and by the way profit and growth, as indicators of business performance, evolved. At a later stage, the results are analysed and commented upon. Finally, the conclusions are presented and some further research proposed.

\section{Literature review and working hypotheses}

Sviokla (1996) stated that the devising of a model that can predict the successful implementation of any new technology is almost as great a challenge as inventing a general-purpose machine that has the ability to think. The different degrees of complexity of the various systems, the fact that the objectives pursued by the adoption of AMT could be specific to each case and that the ways of accessing the new technologies may also be very different, mean that it could not be any other way. In addition, a number of studies (Brynjolfsson and Hitt 1995, Parthasarthy and Yin 1996, Small and Yasin 1997, McDermott and Stock 1999, Schroder and Sohal 1999) demonstrate how differences in business practice and type of organization can to a certain extent explain variations in the competitive performance of AMT users.

Nevertheless, a number of frameworks for action have been devised within which the activities to be carried out during the adoption process for flexible technologies should be included. They provide general guidelines to help companies with this task (Meredith 1987a, Fry and Smith 1989, Paul and Suresh 1991, Motteran and Sizer 1992, Elango and Meinhart 1994, Langley and Truax 1994, Sambasivarao and Deshmukh 1994, Small and Yasin 1997, Sun et al. 1997, Schroder and Sohal 1999). Firstly, these papers for the most part distinguish between the two large phases or stages normally found in any investment process: adoption and implementation. The hypothetical dividing-line between these two phases is marked by the acquisition of the new asset, although it is not easy to make a clear-cut distinction.

As far as the adoption stage is concerned, it is crucial to highlight the importance of pre-investment actions and conditions, not only for the investment to be made, but also for it to be successful. Amongst other aspects, the company should focus on a preliminary study during adoption that allows it to decide on the suitability of adding the new asset to its technological portfolio. This should include strategic planning and staff consultation as well as other more general aspects related to management skills, attitudes and the technology it already has available (Voss 1986). The implementation stage should represent the transitional period during which members of the organization affected by the innovation are trained and commit themselves to its use (Klein and Sorra 1996). This is therefore the crucial link between the decision to adopt the innovation and its later routine use. All efforts should be directed at ensuring the most effective and efficient introduction of the new system possible (one of the issues looked at during the later monitoring stage). Success in this aspect will to a great extent be dependent upon the quality of the analysis made during the previous stage. According to Liker et al. (1993), research should be guided by the relative importance of the different aspects of the process. It should also be borne in mind that, although it is difficult to refute that poor 


\begin{tabular}{|c|c|}
\hline Key factors & Sources \\
\hline \multicolumn{2}{|l|}{ Strategic adjustment factors } \\
\hline (1) Explicit operations strategy & {$[\mathrm{D}],[\mathrm{G}],[\mathrm{L}]$} \\
\hline (2) Clear objectives for automation & {$[\mathrm{M}],[\mathrm{N}],[\mathrm{O}]$} \\
\hline (3) Strategic investment analysis & {$[\mathrm{D}],[\mathrm{F}],[\mathrm{J}]$} \\
\hline (4) Investment/strategic plan co-ordination & {$[\mathrm{G}],[\mathrm{M}],[\mathrm{P}]$} \\
\hline \multicolumn{2}{|l|}{ Infrastructure factors } \\
\hline $\begin{array}{l}\text { (5) Appropriate financial and } \\
\text { accounting techniques }\end{array}$ & {$[\mathrm{D}],[\mathrm{J}]$} \\
\hline $\begin{array}{l}\text { (6) Integrated inter-functional } \\
\text { communication }\end{array}$ & {$[\mathrm{A}],[\mathrm{C}],[\mathrm{G}],[\mathrm{J}],[\mathrm{K}],[\mathrm{M}],[\mathrm{P}]$} \\
\hline (7) Previous experience & {$[\mathrm{B}],[\mathrm{H}],[\mathrm{N}],[\mathrm{O}],[\mathrm{P}]$} \\
\hline (8) Staff versatility & {$[\mathrm{M}]$} \\
\hline \multicolumn{2}{|l|}{ Technical organizational adjustment factors } \\
\hline (9) Technical feasibility analysis & {$[\mathrm{B}],[\mathrm{D}],[\mathrm{H}],[\mathrm{M}]$} \\
\hline $\begin{array}{l}\text { (10) Study of impact on } \\
\text { organization }\end{array}$ & {$[\mathrm{B}],[\mathrm{D}]$} \\
\hline (11) Systems integration plan & {$[\mathrm{A}],[\mathrm{C}],[\mathrm{G}],[\mathrm{J}]$} \\
\hline \multicolumn{2}{|l|}{ Planning factors } \\
\hline (12) Implementation plan & {$[\mathrm{G}],[\mathrm{H}],[\mathrm{J}],[\mathrm{L}],[\mathrm{P}]$} \\
\hline (13) Supplier support & {$[\mathrm{B}],[\mathrm{H}],[\mathrm{I}],[\mathrm{J}],[\mathrm{N}],[\mathrm{O}]$} \\
\hline (14) Creation of multifunctional work team & {$[\mathrm{E}],[\mathrm{F}],[\mathrm{I}],[\mathrm{J}],[\mathrm{K}],[\mathrm{L}],[\mathrm{M}],[\mathrm{N}],[\mathrm{O}]$} \\
\hline $\begin{array}{l}\text { (15) Presence of a leader or } \\
\text { person in charge }\end{array}$ & {$[\mathrm{A}],[\mathrm{B}],[\mathrm{C}],[\mathrm{D}],[\mathrm{F}],[\mathrm{G}],[\mathrm{H}],[\mathrm{I}],[\mathrm{J}],[\mathrm{L}],[\mathrm{M}],[\mathrm{N}],[\mathrm{O}]$} \\
\hline (16) Personnel training & {$[\mathrm{B}],[\mathrm{C}],[\mathrm{H}],[\mathrm{I}],[\mathrm{J}],[\mathrm{K}],[\mathrm{L}],[\mathrm{M}],[\mathrm{N}],[\mathrm{O}],[\mathrm{P}]$} \\
\hline \multicolumn{2}{|l|}{ Motivation factors } \\
\hline $\begin{array}{l}\text { (17) Management support } \\
\text { and commitment }\end{array}$ & {$[\mathrm{B}],[\mathrm{F}],[\mathrm{H}],[\mathrm{J}],[\mathrm{L}],[\mathrm{N}],[\mathrm{O}]$} \\
\hline (18) Worker motivation & {$[\mathrm{B}],[\mathrm{H}],[\mathrm{J}],[\mathrm{K}],[\mathrm{N}],[\mathrm{O}]$} \\
\hline (19) Appropriate rewards & {$[\mathrm{C}],[\mathrm{J}]$} \\
\hline
\end{tabular}

\begin{tabular}{|c|c|c|}
\hline [A]: Beatty (1992) & [F]: Nichols and Jones (1994) & [K]: Boyer et al. (1997) \\
\hline [B]: Jiménez et al. (1992) & [G]: Sambasivarao and Deshmukh (1995) & [L]: Hottenstein et al. (1997) \\
\hline [C]: Shani et al. (1992) & [H]: Martínez Sánchez (1996) & [M]: Small and Yasin (1997) \\
\hline [D]: Slagmulder and Bruggeman (1992) & [I]: Sohal (1996) & {$[\mathrm{N}]:$ Zhao and Co (1997) } \\
\hline [E]: Maffei and Meredith (1994) & [J]: Udo and Ehie (1996) & $\begin{array}{l}{[\mathrm{O}]: \text { Co et al. }(1998)} \\
{[\mathrm{P}] \text { : Burcher } \text { et al. }(1999)}\end{array}$ \\
\hline
\end{tabular}

Table 1. Key factors in adopting and implementing AMT (compiled by authors).

implementation can be the end of a good design, neither can it be stated that a poor design can be made up for by optimum implementation. Nevertheless, some people do continue to say that the implementation phase is the least understood part of the overall innovation process, despite over 40 years of research into the subject (Jayanthi and Sinha 1998).

Regarding the specific factors that should be considered at each stage, more than a decade has gone by since the initial surveys were carried out [a broad compilation of works carried out since the beginning of the eighties can be found in Meredith (1987b)]. However, the latest surveys (see table 1) still highlight the very same problems that were prevalent at that time, namely a lack of strategic far-sightedness, and planning and integration (Álvarez Gil 1995), to a greater or lesser degree. After studying the experiences of companies located in a wide variety of industrial countries all round the world, and with different records as far as industrialization is concerned, Burcher et al. (1999) in effect concluded that there 
are many more similarities than differences in the actions taken when implementing AMT.

As table 1 shows, a total of 19 different factors have been identified although, as yet, no conclusive results have been reached regarding the degree to which they have a positive effect on the result of investments in the factories where AMT were implemented. There are various reasons for these diverging results. On the one hand, there is the undeniable lack of empirical studies and this is exacerbated by the fact that even though a response rate of not less than $50 \%$ is usually recommended (Flynn et al. 1990), this is rarely achieved. On the other hand, the studies that have been conducted do not usually cover the complete adoption and implementation process. This means that to achieve an overall picture of the process it is necessary to resort to studies with extremely different objectives and conducted using different methodologies (Machuca and Sacristán Díaz 1998). These two defects - the lack of studies with a wide sample-base and the lack of studies which provide a complete working framework - are accepted as the norm by a range of authors, both in literature specifically dealing with innovation implementation (Klein and Sorra 1996, Vokurka et al. 1998), and that dealing with generic studies of practices in the area of operations (Bolden et al. 1997). Nevertheless, more ambitious projects with a wider scope would probably have a negative effect on the response rate as longer questionnaires would be required which would, presumably, be more complex to fill out. It would seem that two of the issues that are still pending are the finding of a balance, and an increase in company participation.

The 19 factors shown in table 1 have been grouped into five categories depending on their characteristics and using grouping criteria similar to those found in other studies (Udo and Ehie 1996, Boyer et al. 1997, Small and Yasin 1997, Co et al. 1998):

(a) Strategic adjustment factors relating to how much consideration is given to investments on the strategic side of company planning and operations, and to the ability of the company to appreciate the strategic advantages afforded by AMT.

(b) Factors related to infrastructure. These are basic conditions and technical and management support mechanisms which should be available if AMT are to be implemented successfully.

(c) Technical and organizational adjustment factors. This includes all the factors that are aimed at analysing and guaranteeing the compatibility of the new technology with existing assets in the company.

(d) Planning factors. Activities that the company must do and conditions that it must guarantee throughout the whole AMT adoption, implementation and control process.

(e) Motivational factors. Related to the degree of personal interest the workers and management might show in the planned AMT investment.

However, it is not only important to discover which factors are critical, but also to take into consideration the point in time they are applied, that is, during which stage of the adoption and implementation process they are taken into account. If we therefore take the factors in table 1 and analyse the studies in which they are highlighted, they can be grouped together on the basis of whether they are actions to be taken during the adoption phase (such as, for example, strategic analysis, the technical feasibility analysis and the implementation plan) or the 


\begin{tabular}{|c|c|c|c|}
\hline & $\begin{array}{l}\text { Structural and } \\
\text { Organisational } \\
\text { Circumstances }\end{array}$ & Adoption & $\begin{array}{l}\text { Implementation } \\
\text { and Control }\end{array}$ \\
\hline \multirow{4}{*}{$\begin{array}{l}\text { Strategic } \\
\text { adjustment }\end{array}$} & \multicolumn{2}{|c|}{ Explicit Operations Strategy } & \\
\hline & & \multicolumn{2}{|c|}{ Clear objectives for AMT investment } \\
\hline & & Far-sightedness and strategic analysis & \\
\hline & & Investment/Plans co-ordination & \\
\hline \multirow{4}{*}{ Infrastructure } & \multicolumn{3}{|c|}{ Appropriate financial and accounting techniques } \\
\hline & \multicolumn{3}{|c|}{ Communication and inter-functional integration } \\
\hline & Prior experience & & \\
\hline & \multicolumn{3}{|c|}{ Versatile work-force } \\
\hline \multirow{3}{*}{$\begin{array}{l}\text { Technical and } \\
\text { Organisational } \\
\text { Adiustment }\end{array}$} & & Technical feasibility analysis & \\
\hline & & Study of impact on organisation & \\
\hline & & Plan for systems integration & \\
\hline \multirow{5}{*}{ Planning } & & Planning of implementation & \\
\hline & & \multicolumn{2}{|c|}{ Supplier technical support } \\
\hline & & \multicolumn{2}{|c|}{ Multi-functional team } \\
\hline & & \multicolumn{2}{|c|}{ Presence of leader or person in charge } \\
\hline & & \multicolumn{2}{|c|}{ Personnel training } \\
\hline \multirow{3}{*}{ Motivation } & & \multicolumn{2}{|c|}{ Involvement of top management } \\
\hline & & \multirow{2}{*}{\multicolumn{2}{|c|}{$\begin{array}{c}\text { Personnel motivation } \\
\text { Anpropriate rewards }\end{array}$}} \\
\hline & & & \\
\hline
\end{tabular}

Table 2. Proposed time-line for key factors in AMT adoption and Implementation (Devised by authors).

other activities that are initiated during implementation (such as staff training and motivation or supplier support). Other features or circumstances are, however, specific to the company making the investment which, while possibly facilitating investment in advanced technologies, need not have been motivated by any specific project (amongst these are included an explicit operations strategy, appropriate accounting techniques and previous experience).

Nevertheless, the dividing line between the stages is not always clear-cut since it is not always easy to limit some of these factors to a single part of the process. To give an example: the commitment of the management team to the project is crucial during the whole of the adoption phase, as this will allow it to be taken on board from a strategic point of view. But, moreover, it will still be of vital importance during the implementation phase which follows, when it will continue to be of use in supporting the rest of the personnel involved. An attempt has been made to set this out in table 2. We agree with other authors (Schroder and Sohal 1999) when we state that this issue requires further study, and we shall attempt to go into as great a detail as the study's population size allows.

It is the factors that are taken into account, at whatever point-in-time that may be, that are the starting point for determining their possible positive effect both on the performance of investments and of factories. We therefore formulate the following hypotheses:

H1: The presence of certain factors during AMT adoption and implementation has an effect on the performance of investments.

$\mathrm{H} 2$ : The presence of certain factors during AMT adoption and implementation has an effect on the performance of factories.

If we accept the premise that companies in the Andalusian aeronautical sector behave in a rational way, as stated by Salas (2001), that is, that actions are undertaken in such a way as to maximize opportunities for benefits in whatever way these 
are perceived by the various companies, it should be expected that more effort and resources are devoted to achieving the consolidation of those factors that are believed by these companies to have a greater impact on the performance of their investments; they should also be expected to choose investment options from those that are available to them that would, presumably, result in greater organizational performance.

An analysis of Spanish industry of the decade between 1990 and 2000 has demonstrated that both technology and human capital have been consolidated as variables that explain competition and development (Escorsa et al. 2001). If we accept the findings of previous works, such as that of Guimaraes et al. (1999), for example, we assume that the aeronautical industry (an industry that incorporates the latest technologies with the greatest frequency) would be in line with the position of the Spanish manufacturing industry as a whole at the very least, and we have to accept the following working premise:

If the Andalusian aeronautical industry holds that human resources represent one of the essential factors for achieving success in its investments in new technologies, it will afford special importance to affairs related to the training of said resources, achieving, in this way, incremental performance.

\section{Methodology}

\subsection{Population and data gathering}

The target population is made up of manufacturing plants that were operating in the Andalusian aeronautical sector during the period in which the field work was carried out. Some factors led us to consider that conducting the empirical analysis in the Andalusian aeronautical sector would be particularly interesting and opportune: being extremely technologically intensive and, as such, a potential user of a wide and diverse range of AMT, this sector is strategically important, not only for Andalusian industry, but also for Spain and the European Union as a whole. The target population covered three plants belonging to the CASA Group (Construcciones Aeronáuticas S.A., the Spanish national aeronautical company) and seventeen small and medium-size ancillary companies who supply Spanish aeronautical companies, such as CASA itself, or foreign companies, including Boeing amongst others. In view of the small number of companies, we decided to study the entire population, achieving a $100 \%$ response rate.

The inclusion of the CASA Group factories in the analysis was essential if we were to be able to analyse the whole population. The fact that they all belong to one business group does not distort the results. Although final approval had to be gained from central management, the technical strategy was totally independent for each factory, not only as far as team selection was concerned, but also with regard to team-member evaluation (as was confirmed by the heads of the Engineering Department). It was only once CASA had become part of EADS ${ }^{1}$ (the European Aeronautic, Defence and Space Company) in the year 2000 that each CASA factory was assigned different duties, as well as different degrees of decision-making

\footnotetext{
${ }^{1}$ EADS, which came to being on 10 July 2000, is the largest aerospace company in Europe and the second largest worldwide and emerged from the link-up of the German DASA, the French Aeroespatiale Matra and the Spanish CASA.
} 
responsibility (see www.eads.com for further information). As regards the other 17 ancillary companies, they remain as suppliers of EADS, Airbus, Boeing and other aerospace companies, meaning they possess some special resources and have capabilities that qualify them as relevant players in the international aerospace industry. The restructuring of the European aerospace industry in the last three years and the role that the companies comprised in our population are playing therefore support one of the principal criteria on which we justify its selection: its strategic condition.

The analysis of the research project within which this specific study is encompassed has a relatively wide scope. We therefore decided to break the study into two parts in order to avoid the likely initial respondent resistance to a single, excessively long questionnaire. The basic objective of the first part was to determine the types and extent of AMT being used in the sector, and a postal questionnaire was sent out for this purpose. A preliminary questionnaire was drafted and then submitted to successive tests by external researchers and to a pilot survey. The definitive questionnaire was mailed, to the Managing Director or the Engineering Manager, on 23 July 1999 and the compilation of responses was completed seven and a half months later. Follow-up by telephone enabled doubts to be clarified and contributed to an increase in data reliability.

A second questionnaire was then devised following a similar process, with a view to obtaining the necessary data for the subsequent analysis of the adoption and implementation process of investments made, and for determining the performance of the plants in relative terms. In order to avoid another long period of time compiling responses to the survey and prevent possible problems in interpretation, it was decided to conduct personal interviews for the completion of the questionnaires; this decision was helped by the relatively small number of plants in our population. The questionnaire was sent out beforehand so that respondents could familiarize themselves with its content well before the interview. On this occasion, the process of data collection took less than three months. In most of the smaller ancillary companies, it was the managing director/owner who completed both questionnaires, an advantage that cannot usually be guaranteed in this type of study when the only contact is via mail. It was the engineering manager or assistant engineering manager who attended the interviews at the larger factories.

\subsection{Measurement of variables}

Three types of AMT have been distinguished following the most widely used criteria in research (Boyer and Pagell 2000, Kotha and Swamidass 2000) according to their function or the type of activity in question: design, manufacturing and planning.

As previously stated, the 19 key factors taken into account in AMT adoption and implementation have been theoretically grouped into five main types according to the focus of their effect: strategy, corporate infrastructure, technical and organizational issues, planning, and motivation of personnel. The small number of plants in the population studied led us to analyse all these factors independently in order to test the hypotheses formulated. The effect of each factor on the process was measured on the Likert seven-point scale $(1=$ very negative effect; $4=$ no effect; $7=$ very positive effect).

As in other studies on this subject (e.g. Gupta et al. 1997), we have approached the measurement of investment performance on two levels: one approach is by 
gauging the degree of improvement obtained in the tactical and operational aspects that the plant managers had identified as the principal objectives of the investment. The usual indicators were used to measure strategic operations objectives (Corbett 1996, Roth 1996, Boyer and McDermott 1999, Boyer and Pagell 2000, Ward and Duray 2000), although the opportunity was also provided for other objectives not included in this list to be added (a complete list is available in table 6 below).

It was discovered during the interviews that the companies in question were not excessively clear about what benefits they hoped to derive from the investments they had planned. For Design AMT, only $37.5 \%$ of the user plants were able to point to as many as three specific benefits they expected to obtain after making the investments. This percentage increased to $60 \%$ for Manufacturing AMT and $41.7 \%$ for Planning AMT. These results were obtained only after much insistence, as many companies stated that they had invested simply because they had to, which indicates that the investments had not been wholly thought through beyond the strategic obligation of survival. On this basis, a maximum of three performance indicators have been considered for each plant. The indicators have been measured on the Likert seven-point scale $(1=$ considerable deterioration; $4=$ no change; 7 = considerable improvement).

The second approach was to measure plant performance by means of four indicators, two related to growth (market share and sales) and two to profits (ROI and ROS); the validity of these indicators is supported by previous empirical studies (Boyer et al. 1996, 1997, Gupta et al. 1997, Ward and Duray 2000). For each indicator, the position of the company compared to its competitors over the past three years was measured on a Likert scale of seven points $(1=$ significantly worse; $4=$ similar; $7=$ significantly better).

The fact that this scale had been previously validated in other research - as advised by some (Malhotra and Grover 1998, O'Leary-Kelly and Vokurka 1998, Hensley 1999) - led us to expect, a priori, high levels of inter-item reliability. As a measure of the inter-item reliability of scales, we have employed Cronbach's coefficient $\alpha$, which is by far the most extensively used. Our $\alpha$ value results can be seen in table 3 and in both cases these are notably higher than the 0.7 level usually required for well-established scales (Nunnally 1978, Flynn et al. 1990, Hair et al. 1999).

The validity of the scale was measured by means of content validity. As the use of statistical tools is impossible (Hoskisson et al. 1993: 217) any evaluation of content has to be based on the expert judgement or on references in the literature as to whether the scale in question truly measures the concept or construct for which it was developed. This measurement is therefore by nature subjective and, as such, will

\begin{tabular}{llcc}
\hline Scale & \multicolumn{1}{c}{ Objectives } & Mean & SD \\
\hline Growth & Market share growth & 5.15 & 1.31 \\
$(\alpha=0.8645)$ & Sales growth & 5.45 & 1.19 \\
$($ Scale $)$ & & 5.30 & 1.17 \\
Profit & Return on Investment (ROI) & 4.95 & 1.08 \\
$\quad(\alpha=0.9596)$ & Return on Sales (ROS) & 4.74 & 1.04 \\
$($ Scale $)$ & & 4.84 & 1.04 \\
\hline
\end{tabular}

Table 3. Performance: scales and reliability coefficients. 
always be arguable. The content validity in our research has been checked using previously developed scales, as is recommended by various authors (Flynn et al. 1990, Malhotra and Grover 1998, Hensley 1999).

As far as the point in the process when each factor is taken into account, three possibilities have been distinguished: exclusively during the adoption stage, exclusively during the implementation stage, or during both stages, that is, throughout the whole process.

\subsection{Data analysis}

The testing of hypotheses was performed by applying the Student $t$ statistical test to independent samples. As the complete population is involved, it must be pointed out that the objective of contrasting cannot, by nature, be inferred. It is also important to highlight the fact that the relatively small size of the population does not affect the significance of the contrasts, as the statistics take the size of the sample into account. The SPSS 10.0 statistical program was used for data analysis.

\section{Results and discussion}

\subsection{Factors taken into account for the adoption and implementation of AMT}

Table 4 shows firstly, and in descending order, the proportion of companies that have taken into account each of the key factors when adopting and implementing AMT. Secondly, it shows the point when these factors are taken into account indicating the number of plants (and percentage) that considered them: before acquisition, i.e. exclusively during the adoption process (column A); after acquisition, and therefore solely during the implementation and following control process (column I); or both before and after acquisition, that is throughout the whole of the adoption and implementation process (column $\mathrm{A}+\mathrm{I}$ ). Possessing previous experience is a factor that companies decided not to take into consideration at any time; put bluntly, either they had or they had not previously invested in similar technologies. This factor was therefore not included in this point.

With regard to the first issue, the relevance of personnel versatility is of note, as are the support and commitment of management. These are present in all the plants that employ AMT. Next come personnel training and supplier support, which figure in almost $95 \%$ of the plants. Equally notable is the appearance of an explicit operations strategy in the group of six factors that are least present: only nine of the 19 plants that use AMT, that is to say, less than half the population $(37.5 \%$ in the case of ancillary small and medium-size companies) stated that they had such a strategy. This is a considerably smaller number of firms than those who stated they had a strategic business plan (65\%). This would seem to suggest that, at the very least, the sector's business strategies are lacking, as they do not include the field of operations in their development plans. Another point of interest is that only 11 of the companies that employ AMT stated that they co-ordinated investments they made in these technologies with previously devised strategic plans. If we again turn our attention to the percentage for ancillary companies, we find that it stands at $50 \%$, which means that the remaining $50 \%$ make their investments outside the framework of strategic planning. There is a patent need for greater awareness and training in this respect.

As far as the moment of consideration is concerned, whilst some factors were basically contemplated during the adoption stage and others mainly during the implementation stage, the influence of the majority was felt throughout the whole 


\begin{tabular}{|c|c|c|c|c|c|}
\hline \multirow[b]{3}{*}{ Factor } & \multirow{2}{*}{\multicolumn{2}{|c|}{$\begin{array}{c}\text { Do plants take into account } \\
\text { the factor? } \\
\text { Frequency }(\%)\end{array}$}} & \multirow{2}{*}{\multicolumn{3}{|c|}{$\begin{array}{c}\text { Point at which the } \\
\text { factor is considered } \\
\text { Frequency }(\%)\end{array}$}} \\
\hline & & & & & \\
\hline & Yes & No & A & I & $\mathrm{A}+\mathrm{I}$ \\
\hline Staff versatility & $19(100)$ & $0(0)$ & $4(21.0)$ & $3(15.8)$ & $12(63.2)$ \\
\hline $\begin{array}{l}\text { Management support and } \\
\text { commitment }\end{array}$ & $19(100)$ & $0(0)$ & $3(15.8)$ & $0(0.0)$ & $16(84.2)$ \\
\hline Personnel training & $18(94.7)$ & $1(5.3)$ & $2(11.1)$ & $10(55.6)$ & $6(33.3)$ \\
\hline Supplier support & $18(94.7)$ & $1(5.3)$ & $3(16.7)$ & $5(27.8)$ & $10(55.5)$ \\
\hline Worker motivation & $16(84.2)$ & $3(15.8)$ & $3(18.8)$ & $4(25.0)$ & $9(56.2)$ \\
\hline $\begin{array}{l}\text { Presence of a leader or } \\
\text { person in charge }\end{array}$ & $16(84.2)$ & $3(15.8)$ & $0(0.0)$ & $1(6.2)$ & $15(93.8)$ \\
\hline Clear objectives for automation & $14(73.7)$ & $5(26.3)$ & $7(50.0)$ & $0(0.0)$ & $7(50.0)$ \\
\hline Strategic investment analysis & $13(68.4)$ & $6(31.6)$ & $11(84.6)$ & $0(0.0)$ & $2(15.4)$ \\
\hline Inter-functional integration & $13(68.4)$ & $6(31.6)$ & $1(7.7)$ & $0(0.0)$ & $12(92.3)$ \\
\hline Previous experience & $13(68.4)$ & $6(31.6)$ & - & - & - \\
\hline Implementation plan & $13(68.4)$ & $6(31.6)$ & $9(69.2)$ & $2(15.4)$ & $2(15.4)$ \\
\hline $\begin{array}{l}\text { Investment/Strategic plan } \\
\text { co-ordination }\end{array}$ & $11(57.9)$ & $8(42.1)$ & $11(100)$ & $0(0.0)$ & $0(0.0)$ \\
\hline Multifunctional work team & $10(52.6)$ & $9(47.4)$ & $0(0.0)$ & $0(0.0)$ & $10(100)$ \\
\hline Explicit operations strategy & $9(47.4)$ & $10(52.6)$ & $6(66.7)$ & $0(0.0)$ & $3(33.3)$ \\
\hline $\begin{array}{l}\text { Appropriate financial and } \\
\text { accounting techniques }\end{array}$ & $9(47.4)$ & $10(52.6)$ & $4(44.4)$ & $1(11.1)$ & $4(44.4)$ \\
\hline Technical feasibility analysis & $8(42$. & & $7(87.5)$ & $1(12.5)$ & $0(0.0)$ \\
\hline Study of impact on organization & $7(36.8)$ & $12(63.2)$ & $4(57.1)$ & $2(28.6)$ & $1(14.3)$ \\
\hline Systems integration plan & $7(36.8)$ & $12(63.2)$ & $4(57.1)$ & $1(14.3)$ & $2(28.6)$ \\
\hline Appropriate rewards & $6(31.6)$ & $13(68.4)$ & $2(33.3)$ & $3(50.0)$ & $1(16.7)$ \\
\hline
\end{tabular}

Table 4. Degree to, and point at which, factors considered to be key to AMT adoption (A) and implementation (I) are taken into account.

process. This distribution correlates to a large extent with what was suggested in table 2. In the first group, attention can be drawn to the co-ordination of investment with strategic plans, the technical feasibility analysis, the strategic investment analysis and, to a lesser extent, the implementation plan and having an explicit operations strategy. In the second group can be found training of personnel and the setting of appropriate rewards, although differences are not now so clear-cut. Amongst the factors that can be taken into consideration during both adoption and implementation can be found the presence of a multifunctional work-team and also of a person to take charge of the project, inter-functional integration, and management support and commitment, as well as some other not so well differentiated factors, such as worker versatility, motivation of personnel and supplier support.

The question now is whether it can be stated that the point in the process when the factors were taken into account had any effect on the extent to which they bore influence on it. Table 5 has been drawn up to try and answer this question. It shows the influence each factor had per group of companies according to the time it was taken into consideration.

As can be seen, the averages per factor are relatively similar for each group. This suggests that what is important for the analysed population is the factor itself, and not the point in the process the factor is taken into account. However, the limited 


\begin{tabular}{lccc}
\hline & \multicolumn{3}{c}{ Influence } \\
\cline { 2 - 4 } & $\begin{array}{c}\text { Adoption } \\
\text { mean (SD) }\end{array}$ & $\begin{array}{c}\text { Implementation } \\
\text { mean (SD) }\end{array}$ & $\begin{array}{c}\text { A + I } \\
\text { mean (SD) }\end{array}$ \\
\hline Explicit operations strategy & $5.67(1.36)$ & - & $6.00(0.00)$ \\
Clear objectives for automation & $6.00(1.29)$ & - & $5.71(0.48)$ \\
Strategic investment analysis & $5.82(1.40)$ & - & $6.50(0.70)$ \\
Investment/Strategic plan co-ordination & $5.54(0.82)$ & - & - \\
Appropriate financial and & $4.50(1.00)$ & $5.00(-)$ & $5.25(0.50)$ \\
accounting techniques & - & & \\
Inter-functional integration & $5.25(0.95)$ & $5.00(-)$ & $5.83(0.93)$ \\
Staff versatility & $5.43(1.13)$ & $6.00(-)$ & $5.75(1.21)$ \\
Technical feasibility analysis & $5.00(1.15)$ & $6.5(0.71)$ & $7.00(-)$ \\
Study of impact on organization & $5.75(1.50)$ & $7.00(-)$ & $5.00(0.00)$ \\
Systems integration plan & $5.00(1.00)$ & $4.50(2.12)$ & $5.50(0.71)$ \\
Implementation plan & $5.33(1.15)$ & $6.00(0.71)$ & $5.60(1.89)$ \\
Supplier support & - & - & $5.60(0.84)$ \\
Multifunctional work team & - & $7.00(-)$ & $6.20(0.67)$ \\
Presence of a leader or person in charge & $7.00(0.00)$ & $5.50(1.43)$ & $6.33(0.51)$ \\
Personnel training & $6.33(0.57)$ & - & $6.37(1.25)$ \\
Management support and commitment & $5.67(1.15)$ & $6.25(0.50)$ & $6.22(0.83)$ \\
Worker motivation & $4.50(0.71)$ & $5.67(0.57)$ & $7.00(-)$ \\
Appropriate rewards &
\end{tabular}

Table 5. The influence of key factors according to when they were taken into consideration.

amount of data does not allow us to go into any deeper analysis. On the one hand, the number of elements in each group is in many cases limited to a single companythose where the typical deviation has not been calculated, which is indicated by a (-) - whereas in others, the point where they are taken into consideration is always the same.

It is, therefore, impossible to make any definite statement on this question. It can be noted, however, that some of the averages obtained approached the mean value of the scale (4) very closely, which implies that the perception that companies have of the influence borne by some factors is not overly positive. A mark of 4 indicates that the corresponding factor was present, but that it did not facilitate the introduction of AMT into the company in any way. On some occasions the mark even falls below the mean value, which means that the factors in question were thought to have had a negative effect on the process of introducing a technological asset into the company. This is the case of supplier support, for example. This means that there were cases where, in the opinion of the company acquiring the AMT at least, a bad relationship with the supplier, or a negligent attitude on the supplier's part, made the launch of the equipment more difficult. Answers were also received that barely hid feelings that an implementation plan and training of personnel had a negative influence, which would seem to lack sense. In the specific case of personnel training, the executive we consulted stated that the problem was to be found in the point when said training was done - after the equipment had already been installed in the factory - and he regretted not having been able to train the workers before start-up. As for planning, in some cases the problem arose from the point in time it was done: during the implementation process; this was too late and only after it had been realized that it was necessary to draw up an action plan. In other cases the problem was caused by 


\begin{tabular}{|c|c|c|c|c|c|c|}
\hline \multirow[b]{2}{*}{ Goals or expected benefits } & \multicolumn{2}{|c|}{ Design AMT } & \multicolumn{2}{|c|}{ Manufact. AMT } & \multicolumn{2}{|c|}{ Planning AMT } \\
\hline & Freq. & $\%$ & Freq. & $\%$ & Freq. & $\%$ \\
\hline Fast introduction of new products & 13 & 36.1 & 2 & 5.7 & 1 & 3.8 \\
\hline Improvement in utilization of capacity & 4 & 11.1 & 1 & 2.8 & 5 & 19.2 \\
\hline Consistent quality with low rate of defects & 3 & 8.3 & 7 & 20.0 & 2 & 7.7 \\
\hline Fast deliveries & 1 & 2.7 & 1 & 2.8 & 1 & 3.8 \\
\hline Meeting promised delivery dates & 1 & 2.7 & 6 & 17.1 & 7 & 26.9 \\
\hline Offer a wide range of products & 1 & 2.7 & 3 & 8.6 & - & - \\
\hline Fast changes in designs & 3 & 8.3 & - & - & - & - \\
\hline Reduce production costs & 5 & 13.8 & 6 & 17.1 & 4 & 15.4 \\
\hline Reduce lead times & - & - & 3 & 8.6 & 1 & 3.8 \\
\hline Offering high performance products & 1 & 2.7 & 1 & 2.8 & - & - \\
\hline Supply of reliable products & 2 & 5.5 & 1 & 2.8 & - & - \\
\hline Establishing a culture of quality & - & - & 1 & 2.8 & 1 & 3.8 \\
\hline Increase in labor productivity & - & - & 2 & 5.7 & 1 & 3.8 \\
\hline Improvement of work environment & - & - & 1 & 2.8 & - & - \\
\hline Fast changes in volume & - & - & - & - & 1 & 3.8 \\
\hline Improved budget control & - & - & - & - & 1 & 3.8 \\
\hline Reduction in inventory & 2 & 5.5 & - & - & 1 & 3.8 \\
\hline Number of responses & 36 & 100 & 35 & 100 & 26 & 100 \\
\hline
\end{tabular}

Table 6. Main benefits expected from investment in AMT.

the way it was done: in one particular case the problem was that the planning had not been done properly, and this caused more drawbacks than advantages. Although these examples cannot be used to generalize, they do nonetheless help to illustrate how important it is to consider the key factors in an appropriate way as well as the point in time when they are to be taken into account.

\subsection{Goals for investments}

Table 6 shows results for the objectives that guided each type of AMT investment in the factories in the population. As can be seen, the main advantage the companies that invested in design AMT expected was an increase in new product development, basically, flexibility. The remaining advantages that were expected are equally spread between operational advantages relating to costs and quality. Only two responses indicated that the main objective sought was faster delivery times or meeting delivery dates. For benefits expected from manufacturing AMT, the main objectives were a reduction in production costs, consistent quality and meeting delivery dates, as well as a few other issues relating to flexibility, such as the ability to offer a wide range of products or the speed with which new products are developed. As for the benefits expected from investments made in planning AMT, the responses seem to point to delivery. Nevertheless, other objectives related to reductions in costs are prominent, such as an explicit reduction in production or an increase in the utilization of capacity.

Additionally, the results for the population demonstrate that the expected benefits or objectives that prompt investment in AMT vary depending on the type of technology in question. Investments in design AMT are therefore mainly aimed at greater operational flexibility, which usually comes down to the faster development of new products. Investment in manufacturing AMT is relatively evenly spread between benefits related to costs, quality, flexibility and even delivery. Finally, the 


\begin{tabular}{llccccc}
\hline Variable & AMT & N & Mean & SD & Minimum & Maximum \\
\hline AMT investment & Design & 15 & 6.01 & 0.74 & 4.67 & 7.00 \\
performance & Manufacturing & 14 & 6.33 & 0.73 & 5.00 & 7.00 \\
& Planning & 12 & 5.94 & 0.57 & 5.00 & 7.00 \\
& Total & 19 & 6.08 & 0.52 & 5.00 & 6.83 \\
\hline
\end{tabular}

Table 7. Performance of investment in AMT (degree to which expected benefits were obtained).

motives behind investments in planning AMT seem to be related to meeting delivery dates and costs.

\subsection{Goal achievement: investment performance}

Table 7 shows average investment performance according to the three types of AMT, i.e. design, manufacturing and planning. It is worth noting that average investment performance is similar for all three types of AMT. The lowest value is 5.94, which is quite high on a scale of seven, and corresponds to AMT investment in planning. This would seem to suggest that the companies are, in general terms, quite or very satisfied with the performance obtained from the investments that were made. Another point that supports this view is that the lowest minimum value is 4.67 points (see table 7) for the performance of AMT investments in design. Although this figure is not overly high, it is still above the four-point average for the scale and therefore implies there has been an improvement in the factors that were measured, albeit not a great one. This positive opinion of investments (in no cases were they regretted and none performed negatively) could have erred a little on the positive side because they were, in general terms, limited and incremental. There are indications in other studies (Shepherd et al. 2000) that the more radical the investments are, the poorer is the perception that is had of them. Nevertheless, it must not be forgotten that the figures were gauged on the Likert seven-point scale and based on the opinions of interviewees rather than objective data. Although this is regarded as the lesser of two evils for empirical studies on this subject, it must be borne in mind that the responses received in this way do suffer from a certain subjectivity.

\subsection{Contrasting hypotheses}

$T$-tests were performed on independent samples in order to contrast the hypotheses formulated - that the presence of certain factors during AMT adoption and implementation affects investment performance $(\mathrm{H} 1)$ and plant performance $(\mathrm{H} 2)-$ the results of which can be seen in table 8 .

With respect to $\mathrm{H} 1$, it would appear at first sight that the performance of investment in AMT in this sector is independent of the presence or absence of the great majority of factors that literature has considered to be key to investments of this type. This can be explained to a large extent by taking into account the fact that, in general terms, all the companies in the sector are, as seen above, either quite or very satisfied with the performance achieved by the investments that have been made. There is, nevertheless, at least one factor which allows a partial acceptance of the proposed hypothesis: personnel training. The analysis does, in effect, allow it to be accepted $(p<0.05)$ that investments in AMT made in plants that 


\begin{tabular}{|c|c|c|c|c|c|c|}
\hline \multirow[b]{2}{*}{ Key factor } & \multicolumn{2}{|c|}{$\begin{array}{l}\text { Investment } \\
\text { performance }\end{array}$} & \multicolumn{2}{|c|}{ Growth } & \multicolumn{2}{|c|}{ Profit } \\
\hline & $t$ & $p$-value & $t$ & $p$-value & $t$ & $p$-value \\
\hline Explicit operations strategy & 0.065 & 0.949 & -1.336 & 0.199 & -1.196 & 0.249 \\
\hline Clear objectives for automation & 1.027 & 0.319 & -0.963 & 0.349 & 0.079 & 0.938 \\
\hline Strategic investment analysis & 0.297 & 0.770 & -0.119 & 0.906 & 1.445 & 0.168 \\
\hline $\begin{array}{l}\text { Investment/Strategic plan } \\
\text { co-ordination }\end{array}$ & 0.535 & 0.600 & -1.019 & 0.322 & 0.287 & 0.778 \\
\hline $\begin{array}{l}\text { Appropriate financial and } \\
\text { accounting techniques }\end{array}$ & -0.255 & 0.802 & 0.071 & 0.945 & 1.036 & 0.316 \\
\hline Inter-functional integration & 1.721 & 0.135 & -0.535 & 0.599 & 1.445 & 0.168 \\
\hline Previous experience & 0.213 & 0.834 & 2.513 & 0.022 & 0.000 & 1.000 \\
\hline Staff versatility & - & - & - & - & - & - \\
\hline Technical feasibility analysis & -0.201 & 0.843 & 0.020 & 0.984 & 0.293 & 0.773 \\
\hline Study of impact on organization & -0.479 & 0.638 & -0.230 & 0.821 & 0.515 & 0.613 \\
\hline Systems integration plan & 0.714 & 0.485 & -0.031 & 0.975 & 1.479 & 0.159 \\
\hline Implementation plan & 0.325 & 0.749 & -1.955 & 0.067 & -0.399 & 0.695 \\
\hline Supplier support & 1.545 & 0.141 & 0.317 & 0.755 & -0.155 & 0.878 \\
\hline Multifunctional work team & 0.006 & 0.995 & 0.314 & 0.758 & 0.214 & 0.833 \\
\hline Presence of person in charge & -1.546 & 0.140 & -0.992 & 0.337 & 0.287 & 0.778 \\
\hline Personnel training & 2.178 & 0.044 & -0.546 & 0.592 & 0.792 & 0.440 \\
\hline Management support and commitment & - & - & - & - & - & - \\
\hline Worker motivation & 1.464 & 0.162 & 0.319 & 0.754 & 0.000 & 1.000 \\
\hline Appropriate rewards & 0.443 & 0.664 & -0.715 & 0.484 & 0.227 & 0.823 \\
\hline
\end{tabular}

Table 8. Relationship between investment performance, growth and profit and factors considered to be key ( $t$-test of independent samples, $p<0.05)$.

have conducted personnel training have performed better. Bearing in mind that this performance has been considered satisfactory by the majority of companies in the sector (see table 3), the relationship found can be seen to have a highly explanatory nature, whereby it can be stated that training of personnel is revealed to be a key factor in determining the success of investments in AMT in this sector. Other studies obtain results that confirm the importance of this factor: Guimaraes et al. (1999) note that despite the fact that an increase in a system's complexity can have a negative effect on performance, this negative effect can be mitigated by training operators.

With this relationship established, the effect key factors have on company performance $(\mathrm{H} 2)$ is now analysed, the results indicating that the only relationship that is significant in a statistical sense is that between previous experience and business growth.

This relationship might draw attention to there possibly being a certain learning effect (Salas 2001), which translates into a better implementation of new investments and, consequently, into better investment performance as measured through growth. It may also be deduced that it is specifically those companies with a greater rate of growth and which are in the middle of a period of expansion that invest more and, therefore, have a greater chance of having previous experience when acquiring new AMT. This would, in turn, facilitate the appearance of the aforementioned learning effect. 
As far as profit is concerned, it cannot be deduced that taking into account any of the key factors has any effect at all, either positive or negative. This highlights the fact that business performance is conditioned by circumstances other than investment in AMT as such, or, in other words, it is not enough to invest in AMT for there to be an increase in profit. This situation is prevalent amongst small Spanish companies in fairly general terms (González et al. 1999). It could therefore be said that the adoption of AMT is an essential requirement for remaining in the sector, and that it is, therefore, an order qualifier, whilst at the same time, when linked with the presence of a certain learning effect, it also serves to achieve the objective of greater growth.

\section{Conclusions and future lines of research}

This analysis allows the statement that the versatility of staff and the support and commitment of management are factors that factories in the Andalusian aeronautical sector take into account to a greater extent when adopting, implementing and controlling their investment in AMT. The second group of factors, in order of importance, includes personnel training, supplier support, having a person in charge of the project, and motivation of the workforce. In view of these facts and the results obtained it could be stated that factors related to human resource management, such as versatility, training, motivation and leadership, are the factors that companies perceive as being the most important for achieving their objectives.

At the other end of the scale are to be found the implementation of appropriate rewards, a study of the impact on the organization and the development of an integrated systems plan, a technical feasibility analysis, having an explicit operations strategy and the use of appropriate financial and accounting techniques. This has not had any grave consequences, perhaps due to circumstances that existed until recently surrounding the relative competition between plants; nevertheless, the rapid changes that are occurring in the sector, and the threat of increased competition, either from Spanish or foreign companies, may mean that not taking the above-mentioned factors into account could turn into a serious handicap for ancillary aeronautical companies in Andalusia.

At the same time, this analysis shows that those companies that have undertaken training of their personnel present greater performance on investments in AMT. These results support the hypothesis (Co et al. 1998, Escorsa et al. 2001, Salas 2001) that of all the factors mentioned in the literature as conditioning success, only the human factor can mark a difference between those companies that are successful and those that are less so. At the same time, our working premise would seem to have been confirmed, showing the rationality that exists in Andalusian aeronautical companies. As such, the results obtained do not allow that investments made in AMT are, by themselves, a means for increasing profit, even though investments in certain AMT seem to be indispensable for the survival of many companies in the sector. This situation could be characterized as a case of incremental innovation driven by a demand that could lead to an increase in innovative capacity and future participation in $\mathrm{R} \& \mathrm{D}$ efforts if it were backed up by an appropriate business strategy (Escorsa et al. 2001).

Nevertheless, we have to state here that the majority of the companies in our population are now actively involved in the principal civil and military Airbus programs: the A380 and the A400M, respectively. This means that they have successfully undergone a detailed selection process, and are fully benefiting from the 
interesting and enriching knowledge generated within the entire supply chain: their diversity and openness to change appears to give the companies studied a greater degree of creativity to master new challenges. Here, it is quite important to highlight the fact that Airbus Military is based on the accumulated experience of Airbus in the management of complex international programmes in the field of civil aviation and on the specialized and expert know-how in manufacturing by the rest of the participating companies. Accordingly, both the learning effect and some diffusion of technology (both intentional or otherwise) are expected to take place among the participating facilities.

As far as the specific point of the process where the analysed factors are taken into account is concerned, the following factors stand out in the adoption phase: the co-ordination of the investment and strategic plans, a technical feasibility analysis, a strategic investment analysis, and, to a lesser extent, the planning of implementation phase and having an explicit operations strategy. Staff training, and the fixing of appropriate rewards are reserved for the implementation phase. Amongst those factors taken into account in both the adoption and the implementation phases are the existence of a multi-functional work team, the presence of a person in charge of the project, inter-functional integration, and the support and commitment of the management. These factors seem to be important in themselves and not related to the point in the process when they are taken into account. Nevertheless, the small size of the population used in the study does not allow for a conclusive empirical study, nor for a generalization of the results, which means that the question of whether the point in the process where they are taken into account has any effect on their influence on the process of adoption and implementation still remains open to research. Replications using different sectors and bigger populations and samples will help to improve the external validity of the study.

We have to accept that the fact that our study has been based on both sectoral and regional research means that the extrapolation of the results to any other sample or population is not feasible. Nevertheless, we do believe that these studies arouse interest, as their value lies, precisely, in the possibility of their logical extrapolation to other areas where their findings might apply, and researchers being able to judge whether specific findings might be valid in other circumstances. In our opinion, this could be the case, for example, of the small aerospace companies which are on their way to becoming new members of the EADS supply chain in the near future, which could now be in the process of being adopters and implementers of new AMT, such as small firms which belong to the networks of the Shenyang Aircraft Corporation, the Xian Aircraft Corporation, or the joint venture CASC-Airbus Beijing Service \& Training Center, all of them located in China. It could also apply to some firms in the surroundings of Maroc Aviation (Morocco), small entities in Poland, collaborating with EADS PZL 'Warszawa-Okęcie', or those others which collaborate with Eurocopter Romania. Future studies could analyse whether or not some similarities exist among these companies and the 20 in our focus population as regards their adoption and implementation of AMT.

A complementary research line could be initiated which considers similarities and divergences among European aerospace companies which adopted and implemented AMT in the late 1990s. Various questions could be posed, such as: Were there relevant divergences among Western and Eastern companies? If so, of what type? Other questions might address the time-scale different rates concerning when and how the learning effects and the diffusion of technologies and knowledge appeared, 
as well as other questions regarding the contingent factors surrounding the adoption and implementation of AMT and their later effects on the performance of the companies as manufacturing sites, as well as suppliers of the EADS consortium.

\section{Acknowledgements}

We would like to express our gratitude to all those people and companies who cooperated in the fieldwork, without whose collaboration and interest our project would not have been possible. We also wish to thank Professor José Luis Pérez Díez de los Ríos for his invaluable assistance with the statistical analysis. The authors gratefully acknowledge the useful comments and suggestions from the editor and three anonymous reviewers. This research has been partially funded by the CICYT (Spanish Inter Ministerial Commission of Science and Technology) through project number PB1869 and by the Andalusian Regional Government.

\section{References}

Álvarez Gil, M. J., 1995, Los efectos de las tecnologías de la información y comunicación sobre la producción: nuevos sistemas de producción. Economía Industrial, 303, 53-64.

BeAtty, C. A., 1992, Implementing advanced manufacturing technologies: rules of the road. Sloan Management Review, 33, 49-60.

Bolden, R., Waterson, P., Warr, P., Clegg, C. and Wall, T., 1997, A new taxonomy of modern manufacturing practices. International Journal of Operations and Production Management, 17, 1112-1130.

Boyer, K. K., Leong, G. K., Ward, P. T. and Krajewsky, L. J., 1997, Unlocking the potential of advanced manufacturing technologies. Journal of Operations Management, 15, 331-347.

Boyer, K. K. and McDermott, C., 1999, Strategic consensus in operations strategy. Journal of Operations Management, 17, 289-305.

Boyer, K. K. and Pagell, M., 2000, Measurement issues in empirical research: improving measures of operations strategy and advanced manufacturing technology. Journal of Operations Management, 18, 361-374.

Boyer, K. K., Ward, P. T. and Leong, G. K., 1996, Approaches to the factory of the future. an empirical taxonomy. Journal of Operations Management, 14, 297-313.

BRYNJOlfsson, E. and HitT, L., 1995, Information technology as a factor of production: the role of differences among firms. Economy of Innovation and New Technologies, $\mathbf{3}$, 183-199.

Burcher, P., Lee, G. and Sohal, A., 1999, Lessons for Implementing AMT. Some case experiences with $\mathrm{CNC}$ in Australia, Britain and Canada. International Journal of Operations and Production Management, 19, 515-526.

Cagliano, R. and Spina, G., 2000, Advanced manufacturing technologies and strategically flexible production. Journal of Operations Management, 18, 169-190.

Co, H. C., Patuwo, B. E. and Hu, M. Y., 1998, The human factor in advanced manufacturing technology adoption. International Journal of Operations and Production Management, 18, 87-106.

Corbett, L. M., 1996, A comparative study of the operations strategies of globally- and domestically-oriented New Zealand manufacturing firms. International Journal of Production Research, 34, 2677-2689.

Elango, B. and Meinhart, W., 1994, Selecting a flexible manufacturing system-a strategic approach. Long Range Planning, 27, 118-126.

Escorsa, P., Solé, F. and Surís, J., 2001, Nuevas tecnologías e innovación en las empresas españolas, Papeles y Memorias de la Real Academia de Ciencias Morales y Políticas (12), $103-117$.

Flynn, B. B., Sakakibara, S., Schroeder, R. G., Bates, K. A. and Flynn, E. J., 1990, Empirical research methods in operations management. Journal of Operations Management, 9, 250-284. 
Fry, T. D. and Smith, A. E., 1989, FMS implementation procedure: a case study. IEE Transactions on Industrial Engineering, 21, 288-293.

González, X., Jaumandreu, J., and Pazó, C., 1999, Innovación, costes irrecuperables e incentivos a la I + D, Papeles de Economía Española (81), 155-166.

Guimaraes, T., Martensson, N., Stahre, J., and Igbaria, M., 1999, Empirically testing the impact of manufacturing system complexity on performance. International Journal of Operations and Production Management, 19, 1254-1269.

Gupta, A., Chen, I. J. and Chiang, D., 1997, Determining organizational structure choices in advanced manufacturing technology management. OMEGA International Journal of Management Science, 25, 511-521.

Hair, J. F., Anderson, R. E., Tatham, R. L. and Black, W. C., 1999, Análisis Multivariante, 5th edn (Madrid: Prentice Hall).

Hensley, R. L., 1999, A review of operations management studies using scale development techniques. Journal of Operations Management, 17, 343-358.

Hoskisson, R. E., Hitt, M. E., Johnson, R. A. and Moesel, D. D., 1993, Construct validity of an objective (entropy) categorical measure of diversification strategy. Strategic Management Journal, 14, 215-235.

Hottenstein, M. P., Casey, M. S. and Dunn, S. C., 1997, Facilitation of advanced manufacturing technology: implementation and transfer. Industrial Management, 39, $8-13$.

Jayanthi, S. and Sinha, K. K., 1998, Innovation implementation in high technology manufacturing: a chaos-theoretic empirical analysis. Journal of Operations Management, 16, 471-494.

Jiménez, J., Martínez, A., Navarro, L., Polo, Y. and Tomás, L., 1992, The process of implementing industrial robots in Spanish industry. International Journal of Operations and Production Management, 12, 43-56.

Jonsson, P., 2000, An empirical taxonomy of advanced manufacturing technology. International Journal of Operations and Production Management, 20, 1446-1474.

Klein, K. J. and Sorra, J. S., 1996, The challenge of innovation implementation. Academy of Management Review, 21, 1055-1080.

Krafcik, J. F., 1988, Triumph of the lean production systems. Sloan Management Review, 30, $41-52$.

Langley, A. and Truax, J., 1994, A process study of new technology adoption in smaller manufacturing firms. Journal of Management Studies, 31, 619-652.

Liker, J. K., MajChrzaK, A. and ChOI, T., 1993, Impacts of programmable manufacturing technology: a review of recent studies and contingency formulation. Journal of Engineering and Technology Management, 10, 229-264.

Machuca, J. A. D. and Sacristán Díaz, M., 1998, Aspectos claves en la adquisición e implantación de tecnologías avanzadas de fabricación. un estudio preliminar. Actas del VIII Congreso Nacional de ACEDE, Las Palmas de Gran Canaria, Spain, pp. $171-173$.

Maffei, M. J. and Meredith, J., 1994, The organizational side of flexible manufacturing technology. Guidelines for managers. International Journal of Operations and Production Management, 14, 17-34.

Malhotra, M. K. and Grover, V., 1998, An assessment of survey research in POM: from constructs to theory. Journal of Operations Management, 16, 407-425.

Martínez Sánchez, A., 1996, Adopting AMT: experience from Spain. Journal of Manufacturing Systems, 15, 133-140.

Matthews, J. P. and Foo, S. T., 1991, Equipment dedication and automation: some empirical findings. OMEGA International Journal of Management Science, 19, 475484.

McDermott, C. M. and Sтоск, G. N., 1999, Organizational culture and advanced manufacturing technology implementation. Journal of Operations Management, 17, 521-533.

Meredith, J. R., 1987a, Implementing the automated factory. Journal of Manufacturing Systems, 6, 1-13.

Meredith, J. R., 1987b, Implementing new manufacturing technologies: managerial lessons over the FMS life cycle. Interfaces, 17, 51-62. 
Motteran, G. and Sizer, J., 1992, Evaluating and controlling investments in advanced manufacturing technology. Management Accounting, 70, 26-30.

Nichols, W. and Jones, O., 1994, The introduction of CIM: a strategic analysis. International Journal of Operations and Production Management, 60-61, 29-34.

Nunnally, J. C., 1978, Psychometric Theory (New York: McGraw-Hill).

O'Leary-Kelly, S. W. and Vokurka, R. J., 1998, The empirical assessment of construct validity. Journal of Operations Management, 16, 387-405.

Parthasarthy, R. and Yin, J. Z., 1996, Computer-integrated manufacturing and competitive performance. moderating effects of organization-wide integration. Journal of Engineering and Technology Management, 13, 83-110.

Paul, H. and Suresh, B., 1991, Manufacturing strategy through planning and control techniques of advanced manufacturing technology. International Journal of Technology Management, 6, 233-242.

Rотн, A. V., 1996, Neo-operations strategy. Linking capabilities-based competition to technology. In G. H. Gaynor (ed.), Handbook of Technology Management (New York: McGraw-Hill), chapter 38, pp. 38.1-38.44.

SAlas, V., 2001, Innovación y competitividad en la empresa española. Papeles y Memorias de la Real Academia de Ciencias Morales y Políticas (12), 87-101.

Sambasivarao, K. V. and Deshmukh, S. G., 1994, Strategic framework for implementing flexible manufacturing systems in India. International Journal of Operations and Production Management, 14, 50-63.

Sambasivarao, K. V. and Deshmukh, S. G., 1995, Selection and implementation of advanced manufacturing technologies. International Journal of Operations and Production Management, 15, 43-62.

Schroder, R. and Sohal, A. S., 1999, Organisational characteristics associated with AMT adoption. Towards a contingency framework. International Journal of Operations and Production Management, 19, 1270-1291.

Shani, A. B, Grant, R. M., Krishnan, R. and Thompson, E., 1992, Advanced manufacturing systems and organizational choice: sociotechnical system approach. California Management Review, 34, 91-111.

Shepherd, D. A., McDermott, C. and Stock, G. N., 2000, Advanced manufacturing technology: does more radicalness mean more perceived benefits? The Journal of High Technology Management Research, 11, 19-33.

Slagmulder, R. and Bruggeman, W., 1992, Investment justification of flexible manufacturing technologies: inferences from field research. International Journal of Operations and Production Management, 12, 168-186.

Small, M. H. and Yasin, M. M., 1997, Advanced manufacturing technology: implementation policy and performance. Journal of Operations Management, 15, 349-370.

Sohal, A. S., 1996, Assessing AMT implementations: an empirical field study. Technovation, 16, 377-384.

Sun, H., Huulstad, R. and Frick, J., 1997, Implementations of advanced manufacturing technologies: an empirical study in Norway. Papers from the 4th International Conference of the European Operations Management Association, Barcelona, Spain, pp. 555-560.

Sviokla, J. J., 1996, Knowledge workers and radically new technology. Sloan Management Review, 37, 25-40.

Swamidass, P. M. and Kотна, S., 1998, Explaining manufacturing technology use, firm size and performance using a multidimensional view of technology. Journal of Operations Management, 17, 23-37.

Udo, G. J. and EhIE, I.C., 1996, Advanced manufacturing technologies-determinants of implementation success. International Journal of Operations and Production Management, 16, 6-26.

Vokurka, R. J., O'Leary-Kelly, S. and Flores, B., 1998, Approaches to manufacturing improvement: use and performance implications. Production and Inventory Management Journal, 2nd quarter, 42-48.

Voss, C. A., 1986, Implementing manufacturing technology: a manufacturing strategy approach. International Journal of Operations and Production Management, 6, 17-26. 
WARD, P. T. and Duray, R., 2000, Manufacturing strategy in context: environment, competitive strategy and manufacturing strategy. Journal of Operations Management, 18, $123-138$.

Zнао, H. and Co, H. C., 1997, Adoption and implementation of advanced manufacturing technology in Singapore. International Journal of Production Economics, 48, pp. 7-19. 